\title{
Amelioration of methamphetamine cardiotoxicity by propofol
}

\author{
Fatemeh Shaki $^{1}{ }^{*}$, Motahareh Koohsari ${ }^{2}$ \\ ${ }^{1}$ Department of Toxicology and Pharmacology, Faculty of Pharmacy, Mazandaran University of Medical Sciences, Sari, Iran \\ ${ }^{2}$ Research Student Committee, Mazandaran University of Medical Sciences, Sari, Iran
}

Received: Sep22, 2015, Revised: Oct 21, 2015, Accepted: Nov 17, 2015

\begin{abstract}
Methamphetamine (MET) is a stimulant and one of the most abused drugs in worldwide. MET could cause several organ toxicity such as cardiotoxicity. Oxidative stress has been proposed as the main mechanism for MET toxicity. Propofol as a sedative-hypnotic agent has antioxidant property. In this study, we used propofol for attenuating of MET-induced cardiotoxicity in rats. The groups (six rats in each group) were as follows: control, MET (5 mg/kg IP) and treated groups that were received propofol (5, 10 and $20 \mathrm{mg} / \mathrm{kg}$, IP) and vitamin E, $30 \mathrm{~min}$ before MET administration. After 24 hours, animals were killed, and heart tissue and blood were separated. MET cardiotoxicity was assessed by the evaluation of the levels of lactic acid dehydrogenase (LDH) and creatine phosphokinase (CPK) as cardiac marker enzymes. On the other hand, oxidative stress markers such as reactive oxygen species (ROS), lipid peroxidation (LPO), glutathione (GSH) and protein carbonyl were measured in heart tissue. Treatment with propofol significantly decreased the cardiac marker enzymes level which increased in MET-treated group. Propofol significantly inhibited the ROS formation and protected the cardiac tissue against LPO. Propofol also significantly prevented MET induced GSH oxidation in cardiac tissue. Protein carbonyl level was increased after MET exposure, but was significantly decreased with propofol pretreatment. This study showed that propofol prevented MET-induced cardiotoxicity via inhibition of oxidative stress damage. Therefore, the efficacy of this antioxidant could be evaluated for the treatment of MET toxicity situation.
\end{abstract}

Keywords: Methamphetamine, cardiotoxicity, propofol, oxidative stress, cardiac enzyme

\section{Introduction}

Methamphetamine (MET) is a synthetic amine stimulant that is a highly addictive stimulant. Abuseof MET has increased rapidly worldwide $(1,2)$ and has become a significant health care and legal concernissue with more than 35 million users in worldwide $(3,4)$.
MET could affect multiple organs such as central nervous system and heart tissue. MET using causes hypertension and tachycardia, cardiovascular complications such as myocardial infarction, dysrhythmias, ventricular hypertrophy, pulmonary edema and 
hypertension, cerebral stroke and hemorrhage, seizures, psychosis, and occasionally (2) death may occur.

Previous studies have demonstrated that an increase in catecholamine activity in the branch of the peripheral nervous system is the primary mechanism responsible for MET cardiotoxicity. In fact, high concentration of catecholamine is cardiotoxic and causes narrowing and spasm of the blood vessels, tachycardia, hypertension and probably, death of the cardiomyocyte. Other features of catecholamine toxicity include the formation of fibrous tissue and an increase in the size of heart muscle cells (5).

On the other hand, it has been shown that oxidative stress plays a major role in the molecular toxicity of MET(6). Reactive oxygen species (ROS) and quinones can be generated by autooxidation and enzymatic oxidative metabolism of dopamine that overwhelm the antioxidant defense systems and lead to oxidative stress. MET-induced oxidative stress has been shown after administration of MET $(7,8)$. Additionally, Acikgoz et al described an increase in extracellular concentrations of oxidized glutathione after MET administration (9).

Indeed, it was observed that administration of some antioxidants such as vitamin $\mathrm{C}$ and $\mathrm{E}$ partially attenuate MET induced-toxicity (10). In another study, $\mathrm{N}$-acetyl cysteine pretreatment reversed the toxic effects of MET on cells by inhibition of glutathione (GSH) oxidation and reduction of MET-induced ROS formation (4). Eskandari et al showed mitochondrial membrane potential (MMP) collapse and cytochrome c release from mitochondria after MET exposure in rat hepatocytes that was inhibited by antioxidants and ROS scavenger which demonstrate the role of oxidative stress and mitochondrial dysfunction in MET-induced cytotoxicity (11). So, mitochondrial dysfunction can be linked to MET toxicity and even MET induced-ROS formation causes exacerbation of mitochondrial damage which leads to failure of energy hemostasis and an increase in oxidative stress.

There are numerous antioxidants used in clinical studies for attenuating situation that oxidative stress damage is involved. In this study, we have focused on the protective role of propofol against MET induced-oxidative stress in cardiac tissue.

Propofol (2, 6-diisopropylphenol) (Fig. 1) is an intravenous sedative-hypnotic agent that is widely used for both induction/maintenance of anesthesia and sedation (12). Propofol's structure contains a phenolic hydroxyl group and thus is similar to some antioxidant compounds such as a-tocopherol (vitamin E). So, several in-vitro and invivo studies showed that this phenolic chemical structure may results to antioxidant activity of propofol (13). Previous studies described that propofol significantly attenuated lipid peroxidation in various experimental models $(14,15)$ that led to cell protection against oxidative stress and elevated the anti-oxidant capacity of plasma in humans (16-17).Also, it has been shown that propofol prevented mitochondrial damage via stabilizing the transmembrane electrical potential (18), attenuating MPT (mitochondrial permeability transition) pore opening (19) and ROS scavenging (20) that finally resulted to suppression of mitochondrion-pathway of apoptosis (21). 
However, there are no studies about the protective effect of propofol against MET induced-cardiotoxicity. Therefore, in this study, the protective role of propofol in MET-induced cardiotoxicity in rats that received MET was investigated.<smiles>CC(C)c1cccc(C(C)C)c1O</smiles>

Figure 1 Chemical structure of propofol

\section{Materials and methods}

\section{Animals treatment}

Male Wistar rats (200-250 g) were kept in an air-conditioned room with controlled temperature of $22 \pm 2^{\circ} \mathrm{C}$ and maintained on a 12:12 h light cycle with free access to food and water. All experimental procedures were conducted according to the ethical standards and protocols approved by the Committee of Animal Experimentation of Mazandaran University of Medical Sciences, Sari, Iran. All efforts were made to minimize the number of animals and their suffering.

Animals were randomly divided into six groups of six animals and the groups were as follows: control group, MET group, MET plus different concentration of propofol group, and vitamin $\mathrm{E}$ group (as positive control). All chemicals were dissolved in normal saline. Dose of vitamin E was 200 $\mathrm{mg} / \mathrm{kg}$ dissolved in olive oil.

One group of animals received only normal saline and was assigned as control. MET was administered (5 $\mathrm{mg} / \mathrm{kg}$ IP) and propofol (5, 10 and 20 $\mathrm{mg} / \mathrm{kg}$, IP) was administered $30 \mathrm{~min}$ before MET. After 24 hours, animals were killed, heart tissue and blood sample were separated and then heart was minced and homogenized with glass handheld homogenizer (22). The biochemical parameters determined included: total protein, ROS, lipid peroxidation, GSH and protein carbonyl. Also, blood samples were collected from each animal and the serum obtained by centrifugation was used for the determination of lactic acid dehydrogenase (LDH) and creatine phosphokinase (CPK) with commercial Kit (Pars Azmon, Iran).

\section{Total protein assay}

Protein concentrations were determined through the Coomassie blue proteinbinding MET od as explained by Bradford, 1976 (23).

\section{Quantification of ROS level}

The ROS level measurement was performed using DCFH-DA as indicator. Briefly, DCFH-DA was added (final concentration, $10 \mu \mathrm{M}$ ) to samples $(1 \mathrm{mg}$ protein $/ \mathrm{ml})$ and incubated for $10 \mathrm{~min}$. The amount of ROS generation was determined through fluorescence spectrophotometer (RF5000U, Shimadzu, Japan) at 485-nm excitation and 520-nm emission wavelength. The results were expressed as fluorescent intensity per $1 \mathrm{mg}$ protein (24).

\section{Measurement of GSH content}

GSH content was determined using DTNB as the indicator and the developed yellow color was read at 412 $\mathrm{nm}$ on a spectrophotometer (UV-1601 PC, Shimadzu, Japan). GSH content was expressed as $\mu \mathrm{M}(25)$.

Measurement of lipid peroxidation 
The content of malondialdehyde (MDA) was determined by thiobarbituric acid reactive substances (TBARS) expressed as the extent MDA of productions during an acid-heating reaction. Briefly, $0.25 \mathrm{ml}$ sulfuric acid $(0.05 \mathrm{M})$ was added to $0.2 \mathrm{~mL}$ samples $(1 \mathrm{mg}$ protein $/ \mathrm{ml})$ afterwards, with the addition of $0.3 \mathrm{~mL}$ $0.2 \%$ TBA. All the microtubes were placed in a boiling water bath for 30 min. At the end, the tubes were shifted to an ice-bath and $0.4 \mathrm{ml} \mathrm{n}$-butanol was added to each tube. Then, they were centrifuged at $3500 \times \mathrm{g}$ for $10 \mathrm{~min}$. The amount of MDA formed in each of the samples was assessed through measuring the absorbance of the supernatant at $532 \mathrm{~nm}$ with an ELISA reader (Tecan, Rainbow Thermo, Austria). Tetramethoxypropane (TEP) was used as the standard and MDA content was expressed as $\mathrm{nmol} / \mathrm{mg}$ protein (26).

\section{Protein carbonyl}

For determination of protein carbonyl by spectrophotometric method, $200 \mu \mathrm{L}$ of embryo tissue were needed to homogenate. Samples were extracted in $500 \mu \mathrm{L}$ of $20 \%(\mathrm{w} / \mathrm{v}) \mathrm{TCA}$. Then, they were placed at $4^{\circ} \mathrm{C}$ for $15 \mathrm{~min}$. The precipitates were treated with $500 \mu \mathrm{L}$ of $0.2 \% \mathrm{DNPH}$ and $500 \mu \mathrm{L}$ of $2 \mathrm{~N} \mathrm{HCl}$ for control group, and the samples were incubated at room temperature for $1 \mathrm{~h}$ with vortexing at 5-min intervals. Then, proteins were precipitated by adding 55 $\mu \mathrm{L}$ of $100 \%$ TCA. The micro-tubes were centrifuged and washed three times with $1000 \mu \mathrm{L}$ of the ethanol-ethyl acetate mixture. The micro-tubes were dissolved in $200 \mu \mathrm{L}$ of $6 \mathrm{M}$ guanidine hydrochloride. The carbonyl content was determined by reading the absorbance at $365 \mathrm{~nm}$ wavelength (27).

\section{Statistical Analysis}

Results were presented as mean \pm SD. All statistical analyses were performed using the SPSS software, version 21. Assays were performed in triplicate and the mean was used for the statistical analysis. Statistical significance was determined using the one-way ANOVA test, followed by the post-hoc Tukey test. Statistical significance was set at $\mathrm{P}<0.05$.

\section{Results}

\section{Cardiac marker enzymes}

Administration of MET to rats significantly increased the levels of cardiac injury markers (LDH and CPK levels). Treatment with propofol $(20 \mathrm{mg} / \mathrm{kg})$ significantly $(\mathrm{p}<0.05)$ decreased the levels of LDH and CPK in MET-treated animals as compared to MET group (Fig.2). In animals treated with vitamin E, no significant changes in the cardiac marker enzymes were observed as compared with MET-treated group.

\section{ROS formation}

As shown in Fig.3, MET exposure increased ROS formation as compared with control group ( $\mathrm{p}<0.05$ ), whereas propofol pretreatment at doses 5 and 10 $\mathrm{mg} / \mathrm{kg}$ didn't cause significant change in ROS formation as compared with MET group. But pretreatment with $20 \mathrm{mg} / \mathrm{kg}$ of propofol resulted in significant reduction of MET-induced ROS formation as compared with MET group $(\mathrm{p}<0.05)$. Also, vitamin E administration significantly $(\mathrm{p}<0.05)$ decreased MET induced-ROS formation.

\section{Lipid peroxidation}

Administration of MET significantly increased the MDA level as compared with control group ( $p<0.05)$. Pre- 

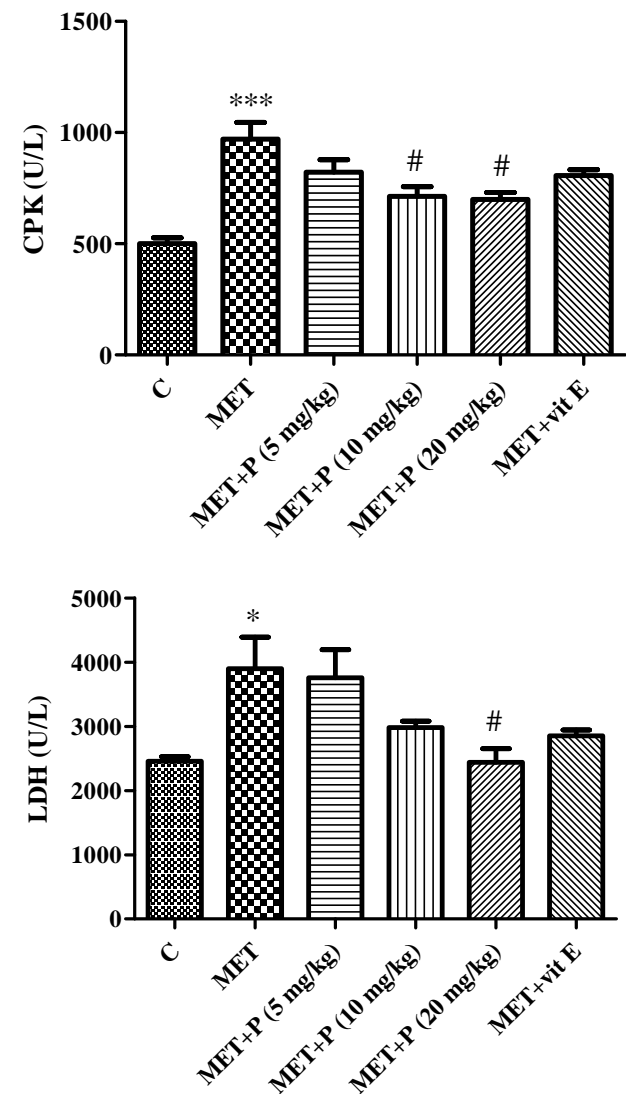

Figure 2 Effects of propofol $(\mathrm{P})$ and vitamin E (Vit E) on methamphetamine (MET)induced toxicity on cardiac marker enzymes. Data were expressed as mean \pm SEM $(n=6)$. *Significantly different from control group (P $<0.05), \quad * * *$ significantly different from control group $(\mathrm{P}<0.001),{ }^{\#}$ significantly different from Methamphetamine group $(\mathrm{P}<$ $0.05)$

treatment with propofol decreased MET induced-LPO as dose dependent manner that was significant $(\mathrm{p}<0.05)$ at doses of 10 and $20 \mathrm{mg} / \mathrm{kg}$. Propofol at doses of $5 \mathrm{mg} / \mathrm{kg}$ did not have any effect on MET induced-LPO. The same effect was observed by administration of vitamin E (Fig.4).

\section{GSH concentration}

Administration of MET significantly decreased the GSH content as compared with control group $(\mathrm{p}<0.05)$. Pretreatment with propofol decreased MET

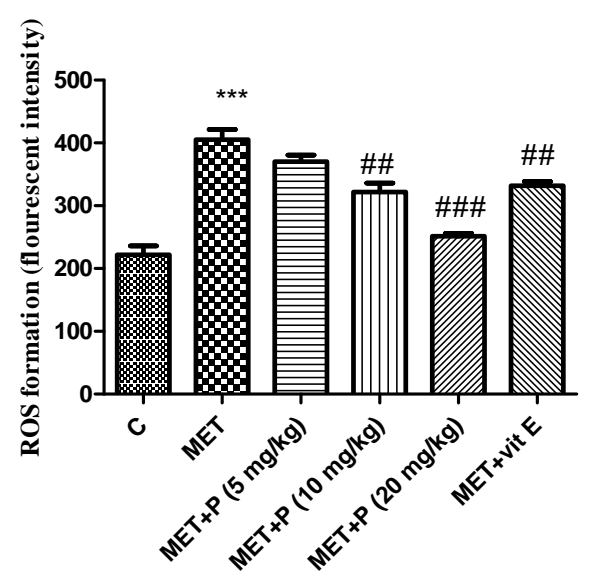

Figure 3 Effects of propofol $(\mathrm{P})$ and vitamin $\mathrm{E}$ (Vit E) on methamphetamine (MET)induced ROS production in heart tissue Data were expressed as mean \pm SEM $(n=6)$. ROS production was evaluated by DCF as indicator as described in Materials and Methods. ***Significantly different from control group $(\mathrm{P}<0.001)$, ${ }^{\# \#}$ significantly different from Methamphetamine group $(\mathrm{P}<$ 0.01), \#\#\# significantly different from Methamphetamine group $(\mathrm{P}<0.01)$

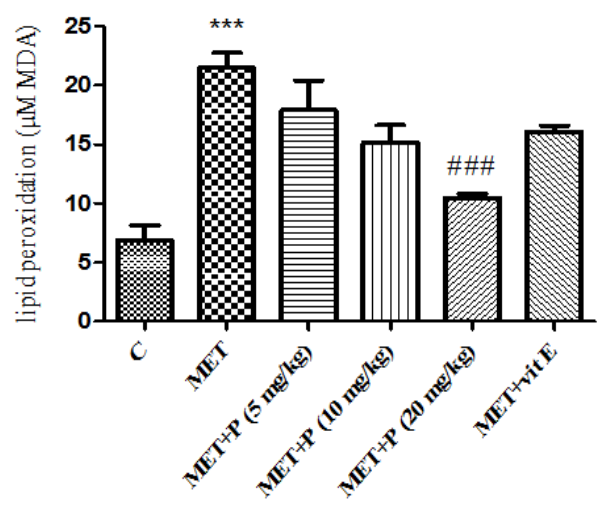

Figure 4 Effects of propofol (P) and vitamin $\mathrm{E}$ (Vit $\mathrm{E}$ ) on methamphetamine (MET)-induced lipid peroxidation in heart tissue. Data were expressed as mean \pm SEM $(n=6)$. Lipid peroxidation was evaluated by TBA as indicator as described in Materials and Methods. ***significantly different from control group $(\mathrm{P}<0.001)$, \#\#\# significantly different from methamphetamine group $(\mathrm{P}<0.001)$ 
induced-GSH oxidation as dose dependent manner that was significant $(\mathrm{p}<0.05)$ at dose of $20 \mathrm{mg} / \mathrm{kg}$. Administration of vitamin $\mathrm{E}$ did not significantly change GSH content when compared with MET group (Fig.5).

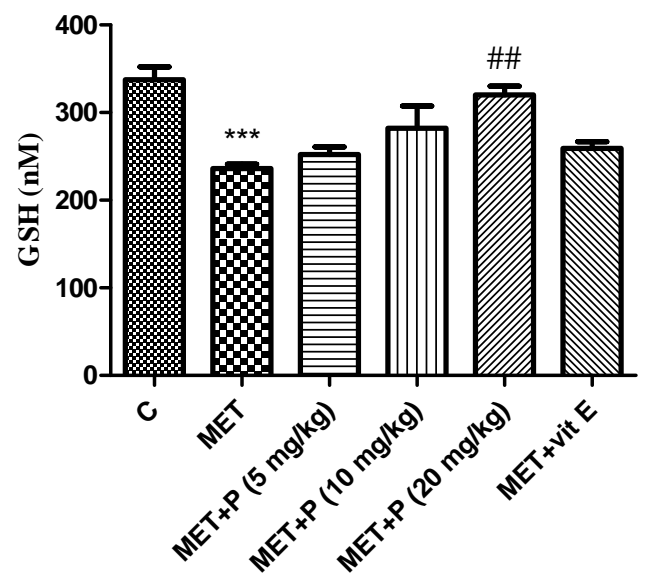

Figure 5 Effects of propofol $(\mathrm{P})$ and vitamin $\mathrm{E}$ (Vit E) on methamphetamine (MET)induced GSH oxidation in heart tissue. Data were expressed as mean $\pm \operatorname{SEM}(n=6)$. GSH content was evaluated by DTNB as indicator as described in materials and methods. ***Significantly different from control group $(\mathrm{P}<0.001)$, ${ }^{\# \#}$ significantly different from methamphetamine group $(\mathrm{P}<$ $0.01)$

\section{Protein carbonyl concentration}

The protein concentration was found to be increased as a consequence of oxidative stress in MET-treated rats compared with control group $(\mathrm{P}<0.05)$. Also, pretreatment of propofol (20 $\mathrm{mg} / \mathrm{kg})$ significantly $(\mathrm{P}<0.05)$ reduced protein carbonyl level in heart tissue of MET treated rats (Fig.6).

\section{Discussion}

ROS generation is a normal component of oxidative phosphorylation and plays a role in normal redox control of physiological signaling pathways (28). However, excessive ROS generation

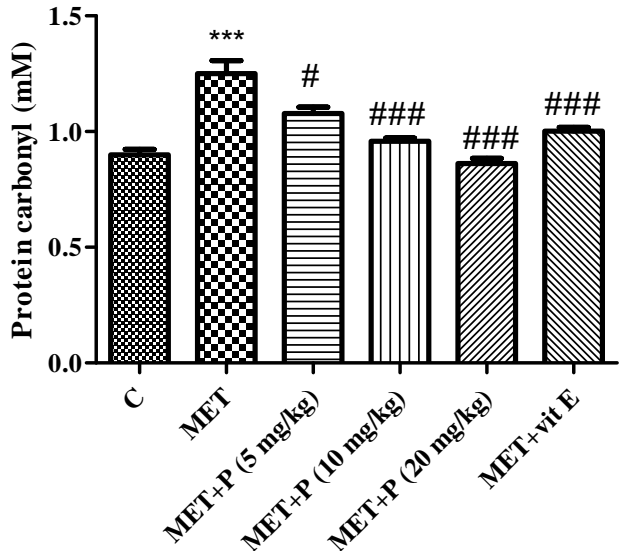

Figure 6 Effects of propofol (P) and vitamin $\mathrm{E}$ (Vit $\mathrm{E}$ ) on methamphetamineinduced protein in heart isolated mitochondria. Data were expressed as mean \pm SEM $(n=6)$. Protein carbonyl content was evaluated by DNPH as described in materials and methods. ***Significantly different from control group ( $\mathrm{P}<0.001)$, ${ }^{*}$ significantly different from methamphetamine group $(\mathrm{P}<0.05)$, \#\#\# significantly different from methamphetamine group $(\mathrm{P}<0.001)$

triggers cell dysfunction, lipid peroxidation, and DNA mutagenesis and can lead to irreversible cell damage or death. Increased formation of ROS indicating the presence of oxidative stress has been observed play a crucial role in cardiac and vascular abnormalities in different types of cardiovascular diseases of experimental and clinical conditions. Furthermore, antioxidant therapy has been shown to exert beneficial (29) effects in hypertension, atherosclerosis, ischemic heart disease, cardiomyopathies and congestive heart failure.

MET abuse is a serious public issue in all parts of the world $(3,4)$ and could causes cardiotoxicity (30). The precise cellular mechanism of MET-induced cardiotoxicity is still unknown. The toxic effects of MET are supposed to occur via various mechanisms (31). 
Recently, studies have documented role of the oxidative stress in MET-induced cardiotoxicity. Also, oxidative damage of mitochondria might be the initial step in tissue damage caused by MET $(31,32)$. In the present study, the role of oxidative stress in MET-induced cardiotoxicity and the ability of propofol on attenuating toxic effects of MET were evaluated.

The results demonstrated the impairment of the antioxidant defense system in heart tissue (decreased GSH) in the MET group. This depletion of the antioxidant system could be as the results of MET induced-oxidative stress demonstrated by an increase in ROS formation and lipid peroxidation. The data confirmed the previous studies that showed MET decreased intracellular GSH, increased MDA levels and intracellular ROS production $(4,33)$. Both in-vivo and in-vitro studies showed that MET increased dopamine release and thereby ROS such as superoxide $\left(\mathrm{O}_{2}{ }^{\circ-}\right)$ and hydroxyl radicals $\left(\mathrm{OH}^{\circ}\right)$ can be created by auto-oxidation of cytosolic free dopamine (31). In addition, both in-vivo and in-vitro studies demonstrated increased oxidative stress after MET exposure in SH-SY5Y neuroblastoma cells (34) and in rat brain tissues $(35,36)$.

Recent studies (29) showed the role of ROS generation due to impaired mitochondrial reduction of molecular oxygen, secretion of ROS by white blood cells, endothelial dysfunction, auto-oxidation of catecholamines, as well as exposure to radiation or air pollution in the cardiac and vascular injury. The findings strongly suggest a central role of oxidative stress in the mechanism underlying MET cardiotoxicity.
Several intrinsic and extrinsic antioxidants have been shown to attenuate the evolution of cardiovascular diseases such as heart failure or hypertrophy in experimental models (37-39). For example, chronic treatment with the nonspecific antioxidant vitamin $\mathrm{E}$ improved cardiac function and blunted heart failure in a guinea pig pressure-overload model. In another study, N-acetyl cysteine prevented cardiac hypertrophy in mice with pressure overload. On the other hand, simvastatin (act as an antioxidant) has been shown to prevent in vitro cardiomyocyte and in vivo pressureoverload-induced hypertrophy.

Previous studies showed that using of some antioxidant such as $\mathrm{N}$-acetyl cysteine, ascorbic acid, vitamin $\mathrm{E}$ and selenium has beneficial effects against MET toxic effects $(10,40,41)$.

Propofol is an intravenous sedativehypnotic agent used for induction and maintenance of general anesthesia as well as for sedation. There is similar structure between propofol and $\alpha$ tocopherol, both contain phenolic hydroxyl group.

This phenolic chemical structure made propofol show antioxidant effects both in-vitro and in-vivo experimental models (12). Recent studies revealed that propofol is able to scavenge free radicals and inhibition of lipid peroxidation (42). On the other hand, it suggested that polyphenols may increase the endogenous antioxidant capacity. On the base of antioxidant effect of propofol, it was used for increased antioxidant capacity, protection against oxidative stress and subsequently prevention of METinduced cardiotoxicity.

As indicated in results section, propofol significantly decreased ROS formation 
and lipid peroxidation in cardiac tissue. These data confirmed earlier reports about the ability of propofol to diminish lipid peroxidation $(15,43)$.

Propofol also significantly inhibited MET-induced GSH oxidation that is linked to induction of expression of antioxidant enzymes (44). Previous studies exhibited that propofol significantly inhibited mitochondrial dysfunction following carbon tetrachloride administration due to its antioxidant effects (20).

In conclusion, propofol via its free radical scavenging and antioxidant properties can be considered as a highly promising agent in protecting against MET-induced oxidative damage .

\section{References}

1. Huang CY, Chen WL, Chen JH, Chang SH, Chan CM. Methamphetamine-Induced Cardiotoxicity with Heart Failure in a Young Adult. A Case Report and Literature Review. J Emerg Crit Care Med 2013;24:62-4.

2. Sadeghi R, Agin K, Taherkhani M, NajmAfshar L, Nelson LS, Abdollahi M, et al. Report of methamphetamine use and cardiomyopathy in three patients. DARU 2012;20:20-4.

3. Barr AM, Panenka WJ, MacEwan GW, Thornton AE, Lang DJ, Honer WG, et al. The need for speed: an update on methamphetamine addiction. J Psychiatry Neurosci 2006;31:301.

4. Zhang X, Banerjee A, Banks WA, Ercal N. $\mathrm{N}$-Acetylcysteine amide protects against methamphetamine-induced oxidative stress and neurotoxicity in immortalized human brain endothelial cells. Brain Res 2009;1275:87-9.

5. Kaye S, McKetin R, Cardiotoxicity associated with methamphetamine use and signs of cardiovascular pathology among methamphetamine users, Technical Report No. 238, National Drug and Alcohol Research Centre, University of New South Wales, Sydney, NSW 2052, Australia.

\section{Acknowledgment}

Funding support of this study was provided by student research committee, Mazandaran University of Medical Sciences.

Conflict of interest

The authors declare that there is no conflict of interest.
6. Riezzo I, Fiore C, De Carlo D, B Karch S, Neri M, Emanuela Turillazi T, et al. The Role of Oxidative Stress in Methamphetamine and MDMA-induced Toxicity. Mini Rev Org Chem 2013;10:349-59.

7. Cubells J, Rayport S, Rajendran G, Sulzer D. Methamphetamine Neurotoxicity Involves Vacuolation of Endocytic Organelies and Dopamine-Dependent Intracellular Oxidative Stress. J Neurosci 1994;74:2260-71.

8. Virmani A, Gaetani F, Imam S, Binienda Z, Ali S. Possible mechanism for the neuroprotective effects of L-carnitine on methamphetamine-evoked neurotoxicity. Ann N Y Acad Sci 2003;993:197-207

9. Acikgoz O, Gonenc S, Gezer S, Kayatekin BM,UysalN,SeminI,etal Methamphetamine causes depletion of glutathione and an increase in oxidized glutathione in the rat striatum and prefrontal cortex. Neurotox Res 2001;3:277-80.

10. De-Vito MJ, Wagner GC, Methamphetamine-induced neuronal damage: a possible role for free radicals. Neuropharmacol 1989;28:1145-50.

11. Eskandari MR, Rahmati M, Khajeamiri AR, Kobarfard F, Noubarani M, Heidari H. A new approach on methamphetamine- 
induced hepatotoxicity: involvement of mitochondrial dysfunction. Xenobiotica 2014;44:70-6.

12. Volti G, Murabito P, Attaguile G, Rodella L, Astuto M, Di Giacomo C, et al. Antioxidant properties of propofol when oxidative stress sleeps with patients. Excli J 2006;5:25-32.

13. De La Cruz J, Zanca A, Carmona J, de la Cuesta FS. The Effect of Propofol on Oxidative Stress in Platelets from Surgical Patients. Anesth Analg 1999;89:1050 -5.

14. Sayin M, Özatamer O, Taşöz R, Kilinc K, Ünal N., Propofol attenuates myocardial lipid peroxidation during coronary artery bypass grafting surgery. $\mathrm{Br} \mathrm{J}$ Anaesth 2002;89:242-6.

15. Manataki A, Tselepis A, Glantzounis G, Arnaoutoglou H, Tsimoyiannis E, Stavropoulos N. Lipid peroxidation and the use of emulsified propofol in laparoscopic surgery. Surg Endosc 2001;15:950-3.

16. Stratford N. Murphy P. Antioxidant activity of propofol in blood from anaesthetized patients. Eur J Anaesthesiol 1998;15:15860.

17. Chen RM, Chen TG, Chen TL, Lin LL, Chang CC, Chang HC, et al. AntiInflammatory and Antioxidative Effects of Propofol on Lipopolysaccharide-Activated Macrophages. Ann N Y Acad Sci 2005;1042:262-71.

18. Branca D, Roberti MS, Lorenzin P, Vincenti E, Scutari G. Influence of the anesthetic 2, 6-diisopropylphenol on the oxidative phosphorylation of isolated rat liver mitochondria. Biochem Pharm 1991;42:87-90.

19. Javadov SA, Lim KH, Kerr PM, Suleiman M-S, Angelini GD, Halestrap AP, Protection of hearts from reperfusion injury by propofol is associated with inhibition of the mitochondrial permeability transition. Card Res 2000;45:360-9.

20. Ranjbar A, Sharifzadeh M, Karimi J, Tavilani H, Baeeri M. Propofol Attenuates Toxic Oxidative Stress by CCl4 in Liver Mitochondria and Blood in Rat. Iran $\mathbf{J}$ Pharm Res 2014;13:253-26.

21. Shaki F, Pourahmad J. Mitochondrial Toxicity of Depleted Uranium: Protection by Beta-Glucan. J Pharm Res 2013;12:131.

22. Shaki F, Hosseini M-J, Ghazi-Khansari M, Pourahmad J, Depleted uranium induces disruption of energy homeostasis and oxidative stress in isolated rat brain mitochondria. Metallomics 2013;5:736-44.

23. Bradford, M.M. A rapid and sensitive method for the quantitation of microgram quantities of protein utilizing the principle of protein-dye binding. Anal Biochem 1976;72:248-54.
24. Gao X, Zheng CY, Yang L, Tang XC, Zhang HY., Huperzine A protects isolated rat brain mitochondria against $\beta$-amyloid peptide. Free Radical Bio Med 2009;46:1454-462.

25. Sedlak J, Lindsay RH. Estimation of total, protein-bound, and nonprotein sulfhydryl groups in tissue with Ellman's reagent. Anal Biochem 1968;25:192-205.

26. Zhang F, Xu Z, Gao J, Xu B, Deng Y. In vitro effect of manganese chloride exposure on energy metabolism and oxidative damage of mitochondria isolated from rat brain. Environ Toxicol Pharmacol 2008;26:232-6.

27. Dalle-Donne I, Rossi R, Giustarini D, Milzani A, Colombo R. Protein carbonyl groups as biomarkers of oxidative stress. Clinica Chimica Acta 2003;329:23-38.

28. Takimoto E, Kass DA. Role of oxidative stress in cardiac hypertrophy and remodeling. Hypertension 2007;49:241-8.

29. Dhalla NS, Temsah RM, Netticadan T. Role of oxidative stress in cardiovascular diseases. J hypertens 2000;18:655-73.

30. Higashi Y, Jitsuiki D, Chayama K, Yoshizumi M. "Edaravone (3-methyl-1phenyl-2-pyrazolin-5-one), a novel free radical scavenger, for treatment of cardiovascular diseases. Recent Patents on Cardiovascular Drug Discovery 2006; 1:8593.

31. Miyazaki, I. M. Asanuma, Dopaminergic Neuron-Specific Oxidative Stress Caused by Dopamine Itself. Acta Med. Okayama 2008;62:141-50.

32. Imam SZ, Islam F, Itzhak Y, Slikker W, Ali SF, Prevention of dopaminergic neurotoxicity by targeting nitric oxide and peroxynitrite: implications for the prevention of methamphetamine-induced neurotoxic damage. Ann N Y Acad Sci 2000;914:157-71.

33. Lee YW, Hennig B, Yao J, Toborek M. Methamphetamine Induces AP-1 and NF$\mathrm{kB}$ Binding and Transactivation in Human Brain Endothelial Cells. J Neurosci Res 2001;66:583-91.

34. Wu CW, Ping YH, Yen JC, Chang CY, Wang S-F, Yeh C-L, et al. Enhanced oxidative stress and aberrant mitochondrial biogenesis in human neuroblastoma $\mathrm{SH}-$ SY5Y cells during methamphetamine induced apoptosis. Toxicol Appl Pharmacol 2007;220:243-51.

35. Fitzmaurice PS, Tong J, Yazdanpanah M, Liu PP, Kalasinsky KS, and Kish SJ. Levels of 4-hydroxynonenal and malondialdehyde are increasedin brain of human chronic users of methamphetamine. J Pharmacol Exp Ther 2006;319:703-09. 
36. Yamamoto, BK, Zhu W. The Effects of methamphetamine on the production of free radicals and oxidative stress. J Pharmacol Exp Ther 1998;2:107-14.

37. Dhalla AK, Hill MF, Singal PK. Role of oxidative stress in transition of hypertrophy to heart failure. J Am Coll Cardiol 1996;28:506-14.

38. Date MO, Morita T, Yamashita N, Nishida $\mathrm{K}$, Yamaguchi $\mathrm{O}$, Higuchi $\mathrm{Y}$, et al. The antioxidant N-2-mercaptopropionyl glycine attenuates left ventricular hypertrophy in in vivo murine pressure-overload model. J Am Coll Cardiol 2002;39:907-12.

39. Takemoto M, Node K, Nakagami H, Liao Y, Grimm M, Takemoto Y,et al. Statins as antioxidant therapy for preventing cardiac myocyte hypertrophy. J Clin Invest 2001;108:1429-37.

40. Fukami G, Hashimoto K, Koike K, Okamura N, Shimizu E, and Iyo M. Effect of antioxidant Nacetyl- L-cysteine on behavioral changes and neurotoxicity in rats after administration of methamphetamine. Brain Res 2004;1016:90-5.
41. Imam, SZ, Ali SF, Selenium, an antioxidant, attenuates methamphetamineinduced dopaminergic toxicity and peroxynitrite generation. Brain Res 2000;855:186-91.

42. Green, TR, Bennett SR, Nelson VM, Specificity and properties of propofol as an antioxidant free radical scavenger. Toxicol Appl Pharmacol 1994;129:163-9.

43. Sayin M, Özatamer O, Taşöz R, Kilinc K, Ünal N. Propofol attenuates myocardial lipid peroxidation during coronary artery bypass grafting surgery. $\mathrm{Br} \mathrm{J}$ Anaesth 2002;89:242-6.

44. Hans P, Deby-Dupont G, Deby C, Pieron F, Verbesselt R, Franssen C, et al., Increase in antioxidant capacity of plasma during propofol anesthesia. J Neurosurg Anesthesiol 1997;9:234-6. 